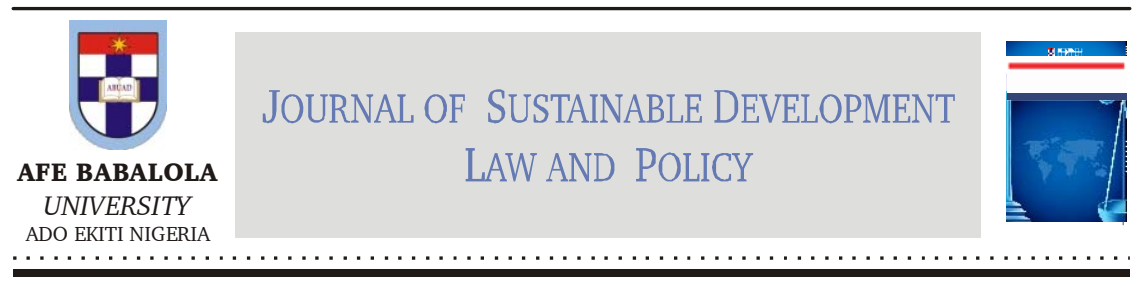

\title{
CONTRIBUTION OF THE EXTRACTIVE INDUSTRY TO SUSTAINABILITY IN THE MIDDLE EAST AND NORTH AFRICAN (MENA) REGION
}

\author{
Adenike A. Akinsemolu*
}

\begin{abstract}
The extractive industry has great potential for mobilizing financial support as well as physical, technological, and human resources to advance the Sustainable Development Goals (SDGs). This article traces developments in the industry with a view to identifying existing gaps in knowledge and the proactive measures needed to ensure that the extractive industry makes a crucial contribution to the society. More specifically, this article explores the historical and current contributions that extractive industries have on social development, political stability, and economic prosperity in the Middle East and North African (MENA) region. Practical and specific examples are used to show the progress made in the attainment or support of the SDGs. The first finding is that the extractive industry in the region has the potential and opportunity to contribute to the attainment of all the 17 SDGs. The second finding is that despite the extractive industry being diverse, the nature and scope of typical activities highlight that various common opportunities can be leveraged on to achieve progress on the SDGs. Thirdly, an unprecedented level of stakeholder cooperation is needed to attain the SDGs. Finally, extractive industries in the MENA region are lagging in furthering SDGs because their activities contribute to environmental degradation.
\end{abstract}

Keywords: Sustainable Development Goals; Mining; Middle East; North Africa; Environmental Sustainability.

DOI: https://dx.doi.org/10.4314/jsdlp.v11i2.10

* Senior Research Fellow, Institute for Oil, Gas, Energy, Environment and Sustainable Development, Afe Babalola University, Ado Ekiti, Nigeria. 


\section{INTRODUCTION}

This article examines the importance of the extractive industry to the attainment of the Sustainable Development Goals in the Middle East and North African region. It evaluates key problems facing the SDGs in MENA extractive industry, and identifies solutions for addressing them.

The MENA region is home to some of the world's largest stakeholders in the two subsectors of the extractive industry: petroleum and solid minerals. ${ }^{1}$ It has about 22 countries, including Yemen, Bahrain, Jordan, Algeria, Djibouti, Egypt, Sudan, Mauritania, Tunisia, Kuwait, Lebanon, Israel, Qatar, Libya, Morocco, Palestine, Saudi Arabia, United Arab Emirates (UAE), Iraq, Iran, Syria, and Oman. ${ }^{2}$ The region is characterized by harsh climatic conditions and limited rainfall but has various natural resources. It also has significant crude oil and gas reserves. ${ }^{3}$ The World Bank classifies many countries in this region as middle-income. On the other hand, the oil-rich states of the Kingdom of Saudi Arabia (KSA), UAE, Qatar, Bahrain, Kuwait, and Oman, are properly classified as highincome nations, while Sudan, Yemen, and Mauritania are classified as low-income countries. ${ }^{4}$ The region also has some of the poorest nations globally, with a yearly per capita income of less than US $\$ 1,500 .{ }^{5}$ By 2014, the region had a population of about 350 million. ${ }^{6}$ The high growth rates of the population have been attributed to the unprecedented increase in the working-age population. The creation of employment remains one of the major priorities in this region because of low youth unemployment. ${ }^{7}$

1 Damilola S. Olawuyi, "Local Content Requirements in Oil and Gas Contracts: Regional Trends in the Middle East and North Africa" (2019) 37 Journal of Energy \& Natural Resources Law 93 <https://www.tandfonline.com/doi/full/ 10.1080/02646811.2018.1477494>.

2 Rami Al-Rawashdeh, Hani Al-Nawafleh and Mohammad Al-Shboul, "Understanding Oil and Mineral Resources in a Political Economy Context: The Case of the Middle East and North Africa (MENA)" [2013] Mineral Economics.

3 Olawuyi (n 1).

4 World Bank, "World Bank Country and Lending Groups" (2019) < https:// datahelpdesk.worldbank.org/knowledgebase/articles/906519> accessed 5 May 2019.

5 Olawuyi (n 1$)$.

6 Sonia Ben Jaafar and Awny Amer, . “. The Role of Monitoring and Evaluation in the MENA Region, with a Focus on the Arab Uprising Countries" in Rob D van den Berg, Indran Naidoo and Susan D Tamondong (eds), Evaluation for Agenda 2030 - Providing Evidence on Progress and Sustainability (IDEAS, UNDP 2017).

7 Al-Rawashdeh, Al-Nawafleh and Al-Shboul (n 2). 
In the MENA region, the extractive industry offers great opportunities for the development of resources, infrastructure, and extractive companies. ${ }^{8}$ It also has the potential to generate socio-economic developmental benefits. Enhancements in exploration technology, as well as strong global demand for these resources, indicate that mineral resources may form a larger share of many nations' exports and national income, especially the prices remain high, but this may not be long-term because of the increased awareness on the need to use sustainable ways of mining and extraction. The extractive industry can be a source of great benefits, as evidenced by Qatar that has witnessed a rise in natural gas production which turned the small nation into an economic hub and superpower. ${ }^{9}$ Similar to Qatar, other countries in the MENA region can capitalize on their strategic location and resources. These countries should capitalize on the available opportunities to their advantage to enhance human development and economic prosperity.

A leading source of minerals and oil, the region is however still embroiled in pollution, political instability, economic stagnation, and lack of social cohesion. ${ }^{10}$ With natural resources being heavily concentrated in the countries found in the region, global firms are increasingly yearning for long-term sustainability. ${ }^{11}$ Many of these states have and continue to witness social unrest due to the inability of the youth to get employment. This is despite the MENA region being strategically located from a geographical standpoint between the influential economies of Europe and India. The strategic location provides them with an edge of improving its mining processes, drawing insights from its neighbours, and embracing sustainability. ${ }^{12}$ Despite hosting a

8 Damilola Olawuyi, "Can MENA Extractive Industries Support the Global Energy Transition? Current Opportunities and Future Directions" (2020) Extractives Industry and Society Journal https://doi.org/10.1016/j.exis.2020.02.003.

9 Onn Winckler, "Qatar: Small State, Big Politics" (2015) 51 Middle Eastern Studies 159 < http://www.tandfonline.com/doi/abs/10.1080/00263206.2014. 959502>.

10 Natalia Yakovleva, Juha Kotilainen and Maija Toivakka, "Reflections on the Opportunities for Mining Companies to Contribute to the United Nations Sustainable Development Goals in Sub - Saharan Africa" (2017) 4 The Extractive Industries and Society $426<$ https://linkinghub.elsevier.com/ retrieve/pii/S2214790X16301526>.

11 Hamid E. Ali and Omnia A. Abdellatif, "Military Expenditures and Natural Resources: Evidence from Rentier States in the Middle East and North Africa" [2015] Defence and Peace Economics; Al-Rawashdeh, Al-Nawafleh and AlShboul (n 2).

12 Ibid. 
significant proportion of global mineral reserves and petroleum, the search for sustainable development in the region remains incomplete. The mining industry of the region faces various challenges, including environmental and social pressure from communities that live close to mines, market volatility, and water scarcity. These are among the factors that deter the development of the region and its attainment of sustainable development. Perhaps, one of the major challenges that is affecting the sustainability of the sector is the unsustainable production of mineral resources. By unsustainable, it means that the methods used in the extraction industry contribute to environmental pollution and degradation, thus harming the health of local communities and populations. ${ }^{13}$ With the increased awareness and the quest for the world to achieve SDGs, this is a significant concern for the sector. Other challenges make it imperative for the region to consider embarking on sustainable measures that can enable them to achieve the 17 SDGs and sustainable development of the region.

Environmental challenges associated with extractive industries in the region have proliferated and accelerated, thus posing risks for future generations' living standards. One of these challenges is the air quality, which remains quite high. The Gulf region is among the most polluted globally because of its addiction to oil and gas. Many of the pollution hotspots are close to oil drilling sites. ${ }^{14}$ According to Malek (2019), ${ }^{15}$ high levels of pollution in the region are attributed to the reliance on fossil fuels from industries and power plants. These challenges have also increased the costs associated with the mitigation of adverse environmental effects. Despite substantial as well as constant awareness and enhancements during the last decade, the region remains under threat because of the dwindling per capita water resources, deterioration of the coastal zones, health issues related to pollution, and susceptible marine resources. ${ }^{16}$ Also, the economic costs associated with environmental degradation remain high. The high costs related to environmental degradation affect household budgets, economic competitiveness, inter-generational equity, and public finances. At the

13 Olawuyi (n 1).

14 C Malek, "For the Gulf Region, Global Air Quality Report Is a Wake-up Call" (Arab News, 2019) < https://www.arabnews.com/node/1506476/middle-east> accessed 10 June 2019.

15 ibid.

16 Olawuyi (n 1). 
current mining and degradation rates, a large proportion of the existing resources will be unavailable in the future. There will be more environmental stresses because of climate change. Notably, MENA remains one of the most vulnerable regions to warming, lower precipitation, and higher sea levels. With the region having the highest water scarcity globally, it is projected that there will be more rivalry for the scarce resources, impact on climate-sensitive agriculture, the vulnerability of urban coastal areas to flooding as well as political turmoil beyond the region.

The world is increasingly becoming interconnected through interlinking technologies, communication, and transportation. The globalization process has numerous implications for economic sustainability, including the supply, demand, and pricing of resources. Population growth and the rise in consumption will only place more pressure on the environment and natural resources in the MENA region, compelling the society to look for more sustainable responses. As a result of these concerns, the formulation of the Sustainable Development Goals was meant to combat the crisis that would arise. The 193 members of the United Nations (UN) endorsed the 17 SDGs. Despite not making it legally binding on Member Countries, the SDGs are significant since they add achievable, common targets for various nations. ${ }^{17}$ They are particularly critical for the extractive industry, which contributes significantly to pollution, natural resource use, and other issues that impact the environment and health of people negatively. One of the major challenges of the MENA region countries is to manage oil extraction and mining in a way that contributes to sustainable development rather than jeopardizing it.

Intrinsically, mining and petroleum companies can become leading partners in the achievement of the SDGs. They can generate economic growth, profits, and employment in the MENA region through their operations. They can also ensure that the benefits accruing from their activities positively affect social capital, the natural environment, and climate change through partnerships with the civil society and government. Similarly, oil extraction and mining corporations can be mandated to adopt safer processes, produce with minimal or no waste, extract with responsibility, apply new sustainable technologies, curb emissions,

17 Robert Costanza, Lorenzo Fioramonti and Ida Kubiszewski, "The UN Sustainable Development Goals and the Dynamics of Well-Being". https://doi.org/10.1002/ fee. 1231 
enhance environmental stewardship, and local communities' wellbeing. Furthermore, the UN stipulates that organizations committed to the SDGs could benefit from better relations with communities and governments as well as gain more access to financial resources. ${ }^{18}$ Contrarily, those that may fail to engage meaningfully on the SDGs will jeopardize their operations not only in the short term but also in the long run.

Three significant issues should be considered while exploring the relationship between the extractive industry and sustainable development in the MENA region. ${ }^{19}$ The first is economic sustainability, which entails attaining long-term sustainability. The second is environmental sustainability, which includes natural resource protection and environmental stewardship. It also involves taking measures that reduce the negative effect of various processes that are related to mineral resource extraction. The final issue is social sustainability, that involves ensuring safe working conditions. The management of mining in all phases requires that MENA countries seriously consider environmental and social consequences. ${ }^{20}$ In the past, contractual and legal frameworks governing mining and petroleum extraction have been made with little or no consideration of the affected communities' wellbeing and environmental sustainability. Also, local communities and the indigenous people have a right in decision-making regarding mining projects, but this is usually not realized. Many nations in the MENA region appear to have embraced rules on social and environmental impact assessment but delay in implementing them.

This article examines the relationship between the extractive industries and the SDGs in the MENA region. The main objective is to explore the historical and contemporary contributions of extractive and mining MENA industries to political stability, social development, and economic prosperity of the region. Section 2 discusses the methodology or approach used in the article. Section 3 is a detailed discussion of the three pillars of the article: economic sustainability, political sustainability, and environmental sustainability. Section 4 explores specific case studies

18 Rafael Fernandes de Mesquita and others, "Mining and the Sustainable Development Goals: A Systematic Literature Review" [2017] Geo-Resources Environment and Engineering.

19 Costanza, Fioramonti and Kubiszewski (n 17).

20 Józef Dubiñski, "Sustainable Development of Mining Mineral Resources" (2013) 12 Journal of Sustainable Mining 1 <https://linkinghub.elsevier.com/retrieve/ pii/S2300396015300446>. 
that preview the three pillars that the article is anchored on and uses them to demonstrate the contribution of the mining and petroleum companies' contribution to sustainable development. In Section 5, recommendations are provided for addressing the challenges that the sector faces and how the countries can position themselves to attain sustainable development. The introduction, case studies, and discussion sections provide insights on the extractive industry in the MENA region and major problems facing the SDGs in the region's petroleum and mining sector. The final section contains recommendations and thus offers solutions for tackling these issues.

\section{RELATIONSHIP BETWEEN MINING AND THE SDGS}

\subsection{Justification}

Bryman (2006) ${ }^{21}$ contends that an array of methodologies, including quantitative, qualitative as well as a mixed-methods approach can be used in research depending on its scope. This article used a systematic review approach to explore the relationship between the extractive industries and SDGs. Ideally, this method is crucial for assessing the current state of research on the extractive industry and SDGs, particularly in the MENA region. The review was crucial for determining what is known and the breadth to which the topic has been studied. It was also crucial for identifying the experts in this topic who can later be consulted in the current research. Thirdly, the review was critical for identifying key questions about the extractive industry that requires more research. The systematic review was also critical for identification, evaluation, and synthesis of research results to summarize the existing evidence that can yield evidence-based practice. Notably, the systematic review uses similar principles and rigour that is required by primary research.

\subsection{Process}

This approach consisted of five major steps: (i) Using the main search terms which are environmental sustainability, North Africa, Sustainable Development Goals, Mining, and the Middle East, on the database, (ii) Organizing papers, and (iii) Determining the relationship between the

21 A Bryman, Mixed Methods (Sage Publications, 2016), pp. 1-20. 
papers. The other critical steps entailed (iv) classifying results from the papers through the content analysis technique, (v) Synthesising and concluding. Notably, the results were categorized into two major groups: most recent studies and the highly cited or referenced ones, to incorporate studies that have the newest contribution to the extractive industry and SDGs field and show the ones that have an academic effect. Bibliometric research was carried out for this study's first three steps. Only studies that met the criteria of the five steps were included in the research. After completing the search, the found studies were refined, excluding editorial material, book chapters, proceeding papers, news items, and reviews. For analysis, only articles were kept. The results of the analyses conducted are provided in the next section. A two-screening process was deployed to identify the relevant studies in reputable journals. In the first step, the search engine relied on was the Scopus database. The articles' themes were the basis for determining the studies that were considered for this article. Google Scholar was used in the second step to cross-check all the sources. The reputable sources were then selected for analysis and review. Classification and evaluation were based on the following aspects: year of publication, the geographical location of the study, and relevance of the source to the research topic.

\subsection{Case Studies}

Explorative case studies were also used to obtain deeper insights into the current trends in the industry. Ideally, the major forms of case studies are exploratory, explanatory, and descriptive. For this article, multiple case studies were used since the region being covered is expansive and consists of various countries. Using one case study would not be effective for finding the representative or suitable information for the research topic. Since the MENA region has various countries that have various contexts, the multiple case study methodology enables the study to carry out an analysis in all the settings. ${ }^{22}$ While a holistic case study can be crucial for comparison, the evidence obtained from multiple case studies could be deemed as stronger and more reliable. To avoid the aspect of biases, only companies that have been operational for at least five years were considered. Due to the availability of numerous companies in the

22 Jenny Stewart, "Multiple-Case Study Methods in Governance-Related Research" (2012) 14 Public Management Review 67 < http://www.tandfonline. com/doi/ abs/10.1080/14719037.2011.589618> 
extractive industry, the contribution of these companies to the economy of the respective countries was considered. The case studies were also carefully chosen to offer the advantage of facilitating comparisons across various cases. ${ }^{23}$ The other criterion used for the selection of the case studies was information access. The ethical implications were addressed by ensuring that research ethics were observed. This included ensuring that any information obtained from other sources was duly cited and referenced.

\section{DISCUSSION}

The sources were categorized following various themes that were relevant to the study topic. Currently, questions still linger on how the production and extraction of resources in numerous MENA countries can be leveraged to accelerate greater social and environmental development in the society. A prolonged period of political instability, particularly after the Arab Spring, which swept across the MENA region, destruction of extraction infrastructure, and environmental pollution concerns have negatively affected sustainable production and the use of extractive resources within some of these countries found in the region. Notably, the reduction of the international crude oil price, scarcity of water, the international quest for low carbon and alternative fuels and energy-efficient production technologies have necessitated the need to address the complex challenges experienced in extractive industries within various resource-reliant MENA societies. Continuous under-pricing of energy and water has contributed to inefficient water use and unsustainable withdrawal levels from the non-renewable groundwater resources. Despite about 85 per cent of the water withdrawals in the region being for agriculture, it has been projected that the value added to the GDP of the region from the sector is not more than 5 per cent. ${ }^{24}$ The increasing dependence on desalination within the Middle East indicates the significance of having effective management of the energy-water nexus, with resultant implications for water and energy security. Notably, the way things will play out during the next decade will be mainly based on the technologies and policies established. Globally, membrane technologies that rely on electricity,

23 Ibid.

24 M. Walton, "Desalinated Water Affects the Energy Equation in the Middle East" (IEA, 2019) < https://www.iea.org/commentaries/desalinated-water-affectsthe-energy-equation-in-the-middle-east > accessed 21 January 2019. 
including reverse osmosis, are the commonest desalination technology installed globally. However, the Middle East remains an exception. Ideally, the low oil and gas cost, as well as the prevalence of co-generation facilities for water and power, implies that the region depends mainly on fossil fuel-based thermal desalination process like multiple-effect desalination or multi-stage flash. About two-thirds of the water obtained from seawater desalination within the region today emanates from fossilfuel thermal desalination, with the rest being from membrane desalination that depends on electricity generated through natural gas. Generally, the Middle East makes up about 90 per cent of the thermal energy utilized for desalination globally, led by Saudi Arabia and the United Arab Emirates. ${ }^{25}$ Despite this, it is worth noting that the deployment of membrane technologies is increasing in this region. Finally, the society is within the early stages of an international energy transition that could lead to radical transformations of mining industries in the region, in the wake of the need to achieve the 17 SDGs by 2030. Thus, the exploration of innovative strategies and approaches for tackling social, environmental, economic, geopolitical, and technological challenges that extractive industries face can be instrumental for plotting a better path towards sustainable reforms.

\subsection{Economic Growth}

In the past, one of the ramifications of mining and petroleum extraction in the MENA region on the political economy was political instability. Minerals and petroleum were viewed as a resource curse, thus leading to the hypothesis that mineral revenues and oil do not result in economic prosperity. ${ }^{26}$ Four major reasons have been provided for the persistence of the resource curse: military spending, corruption, foreign funds outflow, and lack of democracy. ${ }^{27}$ These tend to result in the negative economic growth of the region. Because of the high oil prices during the 1970s, various studies suggest that high economic growth in countries without oil like Tunisia, Jordan, Egypt, and Syria resulted from foreign aid and remittances. Consequently, these nations had slow growth as a result of

25 ibid.

26 Mohamed Sami Ben Ali, L. Cockx and N. Francken, "The Middle East and North Africa: Cursed by Natural Resources?" in Mohamed Sami Ben Ali (ed), Economic Development in the Middle East and North Africa (1st edn, Palgrave Macmillan US 2016) < http://link.springer.com/10.1057/9781137480668>.

27 ibid. 
the reduction in oil prices during the next decade. ${ }^{28}$ Despite an oil boom in the period between 2006 and 2009, the average annual growth in the gross domestic product, GDP, rates for Libya, Kuwait, and Iraq during the period before this boom were higher (1991-2000). Nations such as UAE, KSA, and Kuwait had improvement, but the growth remained slightly weak. Only Iran experienced an average yearly growth between 2001 and 2010, ${ }^{29}$ and it was because of oil discoveries which commenced during the 1990s and contributed substantially to the reduction of poverty and improvement of the standard of living. Thus, it could be observed that an increase in oil revenues leads to higher GDP, but this growth is unsustainable in coping with the fluctuations related to the petroleum market. ${ }^{30}$ High oil prices result in economic prosperity in the short term along with more wealth for exporters, particularly the developing exporting nations. In the oil boom of the 1970s, the economy of Jordan was driven by financial aids and remittances from Gulf States' governments. As a result, Jordan recorded the highest growth in GDP per capita during this period. ${ }^{31}$ Upon the region's oil-rich economies faltering, the economy receded, thus contributing to the negative effect on real GDP per capita. In the aftermath of the early 1990s, Jordan created efforts geared towards structural reforms and stabilization. These reforms lay the foundation for more employment, reduction of poverty, and better welfare of the population. Thus, the GDP per capita growth rose.

Notably, studies suggest that many economies of countries found in the Middle East that are endowed with vast resource wealth have not performed well compared to countries without such resources. For example, a study conducted by Makdisi et al. (2007) ${ }^{32}$ established capital inefficiency, less impact of trade openness to growth, and pronounced effect of the adverse external shocks. The authors also established that countries in the MENA region had weak or poor institutional structures, with limited human capital stock. The MENA nations that highly depend

28 ibid.

29 ibid.

30 Hamid E. Ali and Sara M Sami, "Inequality, Economic Growth and Natural Resources Rent: Evidence From the Middle East and North Africa", Contemporary Issues in Microeconomics (Palgrave Macmillan UK 2016) < http:/ /link.springer.com/10.1057/9781137529718_4>.

31 ibid.

32 Limam I Makdisi S, Fattah Z, "Determinants of Growth in the MENA Countries" in Hashem P Nugent J B (ed), Explaining growth in the Middle East (Elsevier, Amsterdam 2007). 
on resources tend to experience slower economic growth. Thus, despite oil being a crucial resource or source of revenue for many MENA states, various concerns exist on whether its exploitation benefits them and their economic prosperity. The negative correlation established between the dependence on natural resources and economic growth (Gylfason, 2001) $)^{33}$ appears puzzling at first since classical economic theory may predict that the availability of abundant natural resources ought to benefit the economy when mixed with other production factors. Thus, from a historical point of view, minerals and petroleum have not had a significant impact on the economic performance of the MENA region.

Mining, especially oil discovery, has enhanced the strategic significance of MENA nations and helped in the integration of their economies into the world economy. According to Al-Moneef (2006), the socio-economic transformation of MENA nations and their link to major powers has been impacted by oil mining and involvement in the global political economy. Arguably, economic prosperity seems to be the major benefit accrued from mining in the region to MENA countries. The extractive industry has mainly been instrumental in generating new economic opportunities for local communities and citizens through jobs, business development, and training as a result of various mining operations. ${ }^{34}$ This helps to achieve SDG 8 which focuses on decent work and economic growth.

Mining in the MENA region has further been crucial for the attainment of SDG 9 that covers industrialization, innovation, and infrastructure. It has also been crucial for promoting responsible production and consumption despite its impacts still being minimal. Ideally, mining in the MENA region should also be credited with economic prosperity in the current period and diversification through the development of new infrastructure for energy, water, and transport. ${ }^{35}$ In Iran and other Middle East countries, mineral and petroleum extraction have been crucial for providing materials essential for renewable technologies and the chance for organizations to collaborate across the supply chain as a way of reducing waste, reusing, and recycling. The other contribution has been

33 Thorvaldur Gylfason, "Natural Resources, Education, and Economic Development" (2001) 45 European Economic Review $847<$ https:// linkinghub.elsevier.com/retrieve/pii/S0014292101001271>.

34 Ali, Cockx and Francken (n 25).

35 ibid. 
related to SDG 1 on ending poverty, SDG 5 on gender equality, and the goal on reduced inequalities, but Sakr and Sena $(2017)^{36}$ believe that mining had been a significant source of poverty in the war-torn region. Notably, petroleum extraction and mining in the MENA region have been instrumental for generating revenues through royalties, taxes, and dividends for the respective governments. These have been used for investing in socio-economic development apart from offering employment and business opportunities locally. Some mining and oil corporations use an inclusive approach by collaborating with communities to comprehend the actual positive and negative effects of mines. Organizations also provide support to participatory local decision-making processes about mining operations, grievance resolution, equitable benefit allocation, and identify opportunities to influence marginalized groups.

In a nutshell, extraction in the past has been a significant contributor to many of the challenges that the SDGs are attempting to tackle, including population displacements, social inequality, environmental degradation, armed conflicts, corruption, human rights violations, genderbased violence, and worsening economic inequality. However, modern mining and oil companies in the MENA region are increasingly trying to integrate the SDGs into their operations. They have demonstrated that the extraction industry can spur economic prosperity through the provision of decent employment opportunities, manufacturing opportunities, and infrastructure linkages. A substantial proportion of minerals and oil produced as a result of mining are crucial for numerous technologies, creation of infrastructure, agriculture, and energy production. There is still room for further improvement in the region, trying to not only meet the SDGs but also attaining economic prosperity.

\subsection{Political Stability}

The extractive industry in the MENA region has been found to have a negative correlation, whereby the proliferation and success of the extractive sector lead to political instability. This has led to the concept called "resource curse" because extraction tends to be associated with

36 D. Sakr and A. Abo Sena, "Cleaner Production Status in the Middle East and North Africa Region with Special Focus on Egypt" (2017) 141 Journal of Cleaner Production 1074 <https://linkinghub.elsevier.com/retrieve/pii/ S0959652616315013>. 
conflicts that trigger inter-clan, community, national, and regional wars. ${ }^{37}$ Compared to other regions, the MENA region has mainly been defined by military might and hard power. It has been the prevalent case for the modern history of the region and is poised to remain that way for the foreseeable future. Since the Ottoman Empire collapsed about a century ago, the Middle East has been riddled by internal conflicts and regional turbulence. ${ }^{38}$ These conflicts have contributed to the emergence of autocratic models of leadership in the region. The World Bank has indicated that switching from autocracy to democracy would have contributed to a rise in per capita GDP, mainly by encouraging all aspects of the nations ravaged by war to build more organic structures that would make social progress possible. Hypothetically, had the MENA countries opted for democracy around 2015, GDP per capita could have reached 7.8 per cent instead of the 3.3 per cent they post in the absence of democracy.

Natural resources could be a significant factor in creating violence. In many countries found in the MENA region, the abundance of natural resources is a drawback to local populations. Since many do not benefit directly from revenues generated from the resources, the result is high levels of unemployment, as well as resentment or distrust of government. As Figure 1 shows, youth unemployment remains a pervasive and daunting challenge for the region.

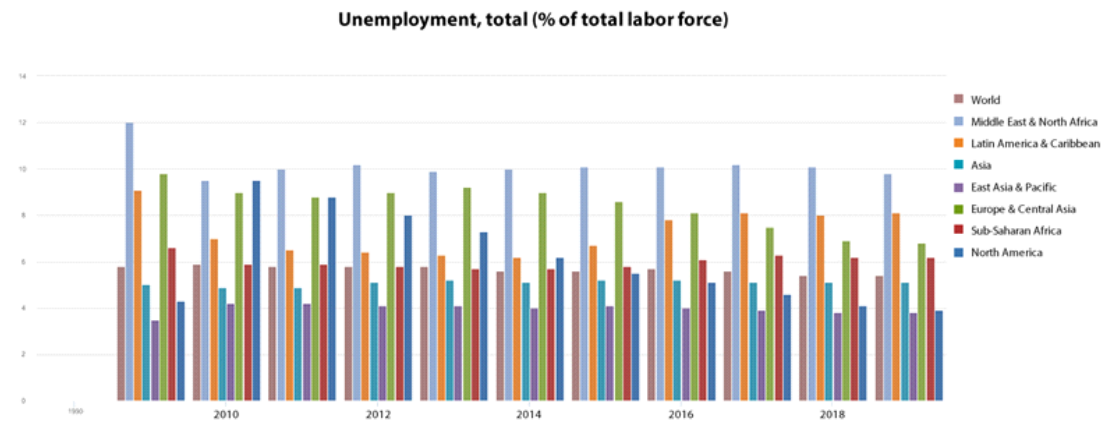

Figure 1: Youth Unemployment in Some MENA Countries Source: World Development Indicator (2019) ${ }^{39}$

37 Jaclyn Johnson and Clayton L. Thyne, "Squeaky Wheels and Troop Loyalty" (2018) 62 Journal of Conflict Resolution 597 <http://journals.sagepub.com/ doi/10.1177/0022002716654742>.

38 ibid.

39 World Development Indicator, "Database" (2019) < https://databank. worldbank.org/home> accessed 18 August 2020. 
Various authors have hypothesized that the production of oil within the region has influenced some groups to either pursue their political or social objectives through nonviolent means or embrace insurgency and terrorism. ${ }^{40}$ Previous studies have also demonstrated that oil-rich nations in MENA have a higher civil war risk and a higher chance of foreign interference. The impact of these oil reserves on political instability has been mainly reliant on group characteristics as well as the reaction of the state or its willingness to negotiate with different political groups that are yearning for change. Using data from 13 countries in the MENA region between 1980 and 2004, Johnson and Thyne (2018) ${ }^{41}$ developed various hypotheses, including the first one, which says insurgencies and terrorism will rise with oil revenues. The second hypothesis is that such violence is controlled or prevented when ordinary citizens take part and benefit from wealth distribution from oil revenues. This implies that sharing power with the people minimizes the level of terrorism. The third hypothesis is that terrorism and violence escalate in accordance to the perceived level of resource discrimination. This implies that the more people are discriminated against economically, the more violence and insurgencies are visited on the state. It also implies that political factors significantly influence terrorism, while economic factors mainly lead to insurgencies. ${ }^{42}$ The other hypothesis is that mineral resources, particularly oil, motivates people to yearn for secession in case of limited autonomy violently. Also, economic discrimination and resource abundance tend to significantly influence terrorist activities but not to civil war. It means that the more robust a state is compared to its dissenting groups, the higher the likelihood of its resorting to terrorism.

The study's results show that ethnopolitical groups found in the MENA region have a higher likelihood of resorting to insurgencies. This is particularly true where the groups have a specific level of political autonomy or get support from an outside government. When groups are involved in power sharing, they have a higher likelihood of opting for nonviolent means of resolving conflicts. Groups with regional autonomy and oil reserves reduce the possibility of terrorism, but the chances of violent conflict could heighten because of financial inducement. ${ }^{43}$ Overall,

40 Johnson and Thyne (n 36).

41 ibid.

42 ibid.

43 Axel Dreher and Merle Kreibaum, "Weapons of Choice" (2016) 53 Journal of Peace Research 539 <http://journals.sagepub.com/doi/10.1177/ $0022343316634418>$. 
these findings suggest that the presence of oil in the MENA region has led to an increase in insurgencies but not terrorism. Insurgencies also act as a factor for mobilizing civil war. Despite economic and political discrimination contributing to a higher probability of terrorism, it is not in any way related to the availability of abundant oil resources.

Turkey, Saudi Arabia, Israel, and Iran could remain influential compared to other states in the region that continue to struggle with instability but will clash on various issues and domestic challenges that will probably influence their regional aspirations. The growing power of Iran, its nuclear capabilities and aggressive behaviour is a major concern for Saudi Arabia, Israel, and various GCC states. Such concerns are aggravated by the sectarianism of regional cooperation between Saudi and Iran. Mineral resources are also driving some of the instability risks in Saudi Arabia, Algeria, and Egypt. ${ }^{44}$ This has been projected to increase in the long-term, particularly in case the oil price remains quite low. The global demands for the energy resources of the MENA region, particularly Asian states, is poised to continue ensuring global engagement and interest within the region. However, external powers will not have the capacity or will to address the numerous problems facing the region. At the same time, some may be attracted to its fights, thus protracting both current and future conflicts.

Sørli, Gleditsch and Strand (2005) ${ }^{45}$ contend that social unrest has significantly impacted extractive industries in the MENA region, and threatens its long-term political stability. The political instability in many parts of this region, especially the destruction and sabotage of infrastructure, has stifled and could continue to stifle the maintenance and development of important infrastructure required for producing and distributing extractive resources. ${ }^{46}$ In the period between 2002 and 2005, the world's attention was caught by the social unrest that emanated from events in Tunisia and later spread to other nations in the region.

44 Tarik M. Yousef, "Development, Growth and Policy Reform in the Middle East and North Africa since 1950" (2004) 18 Journal of Economic Perspectives 91 <https://pubs.aeaweb.org/doi/10.1257/0895330042162322>.

45 Mirjam E Sørli, Nils Petter Gleditsch and Håvard Strand, "Why Is There so Much Conflict in the Middle East?"

46 R. El-Katiri, L. Fattouh, B. Mallinson, The Arab Uprisings and MENA Political Instability-Implications for Oil \& Gas Markets (Oxford Institute of Energy Studies 2014) < https://www.oxfordenergy.org/wpcms/wp-content/uploads/2014/03/ MEP-8.pdf $>$. 
MENA is still grappling with these issues and trying to provide political stability for the current and future generations. One of the major issues that the extractive industry could help solve is water scarcity. About 66 per cent of the population within the region live in areas that lack sufficient renewable water resources for sustaining current consumption levels (a figure that compares in an unfavourable way with the international average of 35 per cent), as shown in Figure 2.

\section{MENA Freshwater Usage: Key figures}

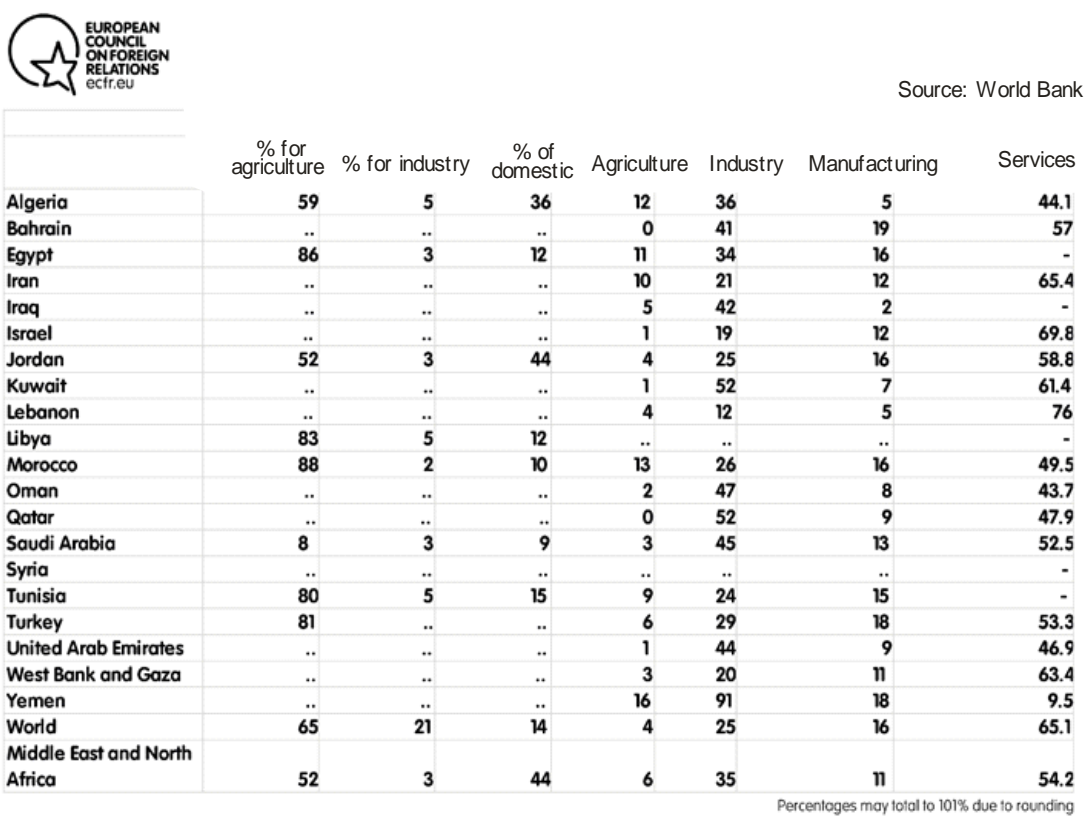

Figure 2: Use of Freshwater in the MENA region

Source: World Bank (2018). ${ }^{47}$

47 World Bank, "Beyond Scarcity: Water Security in the Middle East and North Africa", World Bank Group, 2018" (2018) < https://www.ecfr.eu/publications/ summary/how_water_scarcity_could_destabilise_the_middle_east_and_ north_africa> accessed 24 February $20 \overline{19}$. 
The crises in Libya and Syria have particularly led to the intensification of political tensions within the region and stagnated economic growth. ${ }^{48}$ Consequently, neighbouring states, including Jordan, Lebanon, Tunisia, and Egypt, have received many migrants which have drastically affected labour markets within the region. With high levels of unemployment among the youth, social instability and political tensions will rise within the MENA region into the 2020s. For a larger part of its modern history, the Middle East has been the hotbed of international conflicts. And since the commencement of the early 19th century, European powers have competed among themselves to colonize the territories of the Middle East in an attempt to control the geostrategic location and natural resources. ${ }^{49}$ About 200 years later, the region continues to find itself amid intense crises where the regional and superpowers compete to influence territories. The popular uprisings that occurred during the 2010s have metamorphosed into regional and civil wars within several countries in the region. The increase in violent change, quest to maintain the status quo, and insurgency have been linked to the mineral resources of the region. Notably, the Middle East remains one of the most unstable regions in the world, and prospects for change appear to be dim. The instability is attributed to ongoing conflicts and tension arising from political divisions. Also, the conflicts have resulted from multiple longterm pressures that emanate out of corruption, economic failures, poor governance, as well as other forces within the civil sector. Thus, conflicts in the region have led to the spread of political instability rather than the promotion of stability.

\subsection{Social Sustainability}

During the last few decades, a larger part of the MENA region has been characterized by labour unrest, protests, movements for autonomy, secession, and demands for development. There have been increased calls for greater participation, local content, better working conditions, and improved standards of living in resource-producing communities. A larger proportion of these demands has been on the improvement of the local conditions through mechanisms that seek to achieve Qatarization, Emiratization, and Saudization. ${ }^{50}$ Whereas these incidents have

48 Yousef (n 44).

49 Sørli, Gleditsch and Strand (n 45).

50 Olawuyi (n 1). 
demonstrated various grievances, a closer analysis of the nature of the demands illustrates some recurring themes in particular localities in the MENA region (as demonstrated by Emiratization and Saudization that have peaked in recent years). It is particularly evident in regions that have vast natural resources. For example, people found in Sheba and Hadramawt in Yemen, the Eastern Province of Saudi Arabia, Kurdish Region of Iraq and Deir el-Zour in Syria, and Barca in Libya have all suggested that they are lagging in social development, even though they have vast resource revenues. ${ }^{51}$ They also contend that they have been victims of the pollution attributed to the extraction of certain minerals and petroleum. States protested that organizations were directing revenues from lands where they are generated and depriving these countries of the required wealth and capital. Ideally, resource nationalization seems to retain more revenues at the local level. And whereas resource nationalism justifies the states' efforts to retain control over natural resources from international organizations, many local communities in regions rich in resources currently echo resource regionalism to justify the demands for retaining more benefits from the revenues generated from local resources. ${ }^{52}$ The proliferation of resource regionalism depicts a reality whereby spatial inequality is characterized by a high degree of social conflict and fragmentation. Upon the colonial powers retreating, centralized government emerged and continued with a biased development policy that was prevalent during the colonial rule, thus favouring coastal and urban regions at the expense of the remote areas where resources are mainly located.

Revenues were directed from lands that generated them. Given weakening national identity and cohesion, communities living in these lands gained more interest in the retention of more resource revenues, trying to cure their economic and political grievances through the application of the resource nationalism logic. Numerous governments within the MENA region grapple with the challenge of comprehending, accommodating as well as embracing the these underlying pressures which spur resource regionalism. ${ }^{53}$ Ideally, resource regionalism can

51 F. Mills, R. \& Alhashemi, "Resource Regionalism in the Middle East and North Africa: Rich Lands, Neglected People" (Brookings Institution 2018) < https:// www.brookings.edu/wp-content/uploads/2018/03/resource-regionalism-inthe-mena_english_web.pdf $>$.

52 Yousef (n 44).

53 Mills, R. \& Alhashemi (n 51). 
aggravate instability and social fragmentation. If left unaddressed, tensions can change these countries and make them fertile grounds for further conflicts and wars, particularly in case of political shocks that include regime change, partitioning, poplar uprisings, foreign invasions, and extended conflicts. Whereas regionalism does not necessarily have to result in separatism, it could be salient when residents of a sub-state region develop the perception that they belong to a unique "nation." In tackling resource regionalism, governments need to avoid policies that strengthen regionalism and dependence on resources. Thus, there has been limited socio-environmental development in the MENA region because of the resource curse phenomenon that has denied residents the much-needed social growth, cohesion, and development. The current social inequalities need to be addressed along with the disparities that have increased over time.

\section{CASE STUDIES}

\subsection{Ma'aden Company (Economic Growth and Socio- Environmental Development)}

Ma'aden is a Saudi Arabian mining company and one of the fastestgrowing mining organizations in the world. In the Middle East, it is the leading multi-commodity mining and metals organization. The company has grown significantly since 1997 after being established by Royal Decree, which had the mandate of developing the mineral sector of Saudi Arabia beyond petrochemicals and oil. After investing resources and time in developing an integrated mining value chain, the company currently focuses on marketing its products globally, enhancing the return on investment (ROI) and consolidating its resources and experience. Since its establishment, the company has concentrated on aluminium, copper, phosphate, and gold. On the company's website, Ma'aden states that it has constructed a new mining industrial hub called Ras Al Khair and another mining city called Al Shamal, which is found in Saudi Arabia's remote areas. ${ }^{54}$ It also states that it has contributed substantially to the non-oil GDP of the country, created thousands of jobs in a new mining industry, promoted the development of downstream industries, promoted

54 Ma'aden, "The Story of Ma'aden" (2019) < https://www.maaden.com.sa/en/ sustainability/csr> accessed 2 May 2019. 
the development of local communities through education, health, and social initiatives, facilitated the development of numerous small- and medium-sized enterprises, SMEs, in Saudi Arabia, significantly contributed to constructing new infrastructure facilities, and attracted substantial foreign direct investment (FDI) and advanced technology.

From these commitments, it is worth noting that the company plays a critical role in promoting economic growth and socio-environmental development. Ras Al Khair and Al Shamal have particularly been critical in employment creation and economic growth. The company appreciates that mining can have a critical impact on the environment and remains committed to ensuring that its operations have a minimal possible impact on the environment prior to, during, and after mining activities. The commitment to corporate social responsibility (CSR) is founded on employee commitment, ethics, environment, and community commitment. Before commencing operations within an area, the company is usually dedicated to developing a plan to repatriate a site after the completion of its operations. ${ }^{55}$ This is because mining occasionally results in land dereliction and other negative environmental impacts that may harm people. A notable aspect is that Ma'aden performs all its activities according to global environmental standards. The company seeks to continue improving performance to safeguard the environment. From this case study, it can be deduced that some of the extraction firms in the MENA region support sustainability. Ma'aden's acquisition of a fertilizer distribution organization, Mauritius' Meridian Group, is particularly crucial for supporting Saudi Arabia's Vision 2030, a vision that seeks to align with the global Vision 2030.

\subsection{Kettara Mine, Morocco (Sustainable Development)}

The Kettara mine site is found in Morocco's semi-arid climate region. It is a demonstration of the negative environmental impacts associated with mining in North Africa. The exposure of the mines for about 30 years to ambient air has resulted in the development of acid mine drainage that impacts the nearby ecosystems and people living close to the mine. ${ }^{56}$

55 ibid.

56 Rachid Hakkou, Mostafa Benzaazoua and Bruno Bussière, "Acid Mine Drainage at the Abandoned Kettara Mine (Morocco): 1. Environmental Characterization" (2008) 27 Mine Water and the Environment $145<$ http://link.springer.com/ 10.1007/s10230-008-0036-6>. 
Babi, Asselin and Benzaazoua (2016) ${ }^{57}$ contend that to embrace the sustainability challenge, the mining project ought to balance the socioeconomic and environmental benefits and costs. The site suggests that mining has contributed negatively to the socio-environmental paradigm. The stakeholder groups in the Babi et al (2016) ${ }^{58}$ study demonstrated that the Kettara menace indicates that sustainable mining should be treated as a shared responsibility. Whereas there is a negative correlation between mining and sustainable development, in this case, the study shows that adequate environmental protection is significant for sustainable development. Thus, the recommendation in light of the Kettara mining site is that the best environmental management practices should be applied into extraction practices prior to the commencement of mining projects. The most critical inputs that the study highlights are the role of mining organizations in fostering community sustainability, the level of social impacts associated with mining closure, the need to institute measures to reduce health effects on local populations, and considering inter-generational equity.

\subsection{Arab Potash Company, Jordan (Social, Economic and Environmental Sustainability)}

As the eighth largest producer of potash in the world by sheer production volume, Arab Potash Company (APC) has one of the best records in terms of workplace safety, good governance, environmental conservation, and sustainable community development. It was established in 1956 and is registered to mine, manufacture, and market minerals until 2058. Apart from potash, the company further invests in various complementary and downstream industries related to minerals and Dead Sea salts such as bromine and potassium nitrate. ${ }^{59}$ One of its major contribution to economic development is that it hires at least 2000 workers across its locations found in Ghor Al Safi, Amman and Aqaba. In terms of socio-

57 Khadija Babi, Hugo Asselin and Mostafa Benzaazoua, "Stakeholders' Perceptions of Sustainable Mining in Morocco: A Case Study of the Abandoned Kettara Mine" (2016) 3 The Extractive Industries and Society $185<$ https:// linkinghub.elsevier.com/retrieve/pii/S2214790X15300010>.

58 ibid.

59 Worldfolio, "Arab Potash Company Contributes to Jordan's National Development" (2015) < http://www.theworldfolio.com/news/arab-potashcompany-contributes-to-jordans-national-development/3528/> accessed 10 February 2019. 
environmental development, the company engages in various corporate social responsibility ventures. It actively cooperates with local community leaders, NGOs, charities, and government organizations to spur social development in Jordan, especially within the governorates of Ma'an, Karak, and Tafileh. ${ }^{60}$ Its yearly CSR contributions sustain initiatives that are primary geared towards sectors such as health, the environment, water, and education, with a general objective of alleviating poverty (thus contributing significantly to the attainment of the SDG on poverty), raising the standard of living, improving infrastructure, tackling community needs and boosting public services. For example, between 2012 and 2013, the company allocated 10 million Jordanian dinars (JOD) annually to its CSR programmes and activities, which directly benefitted not less than 100,000 citizens and 2000 organizations. Figure 3 shows the company's CSR spending distribution in 2013, thus demonstrating its commitment to the society, environment, and healthcare.

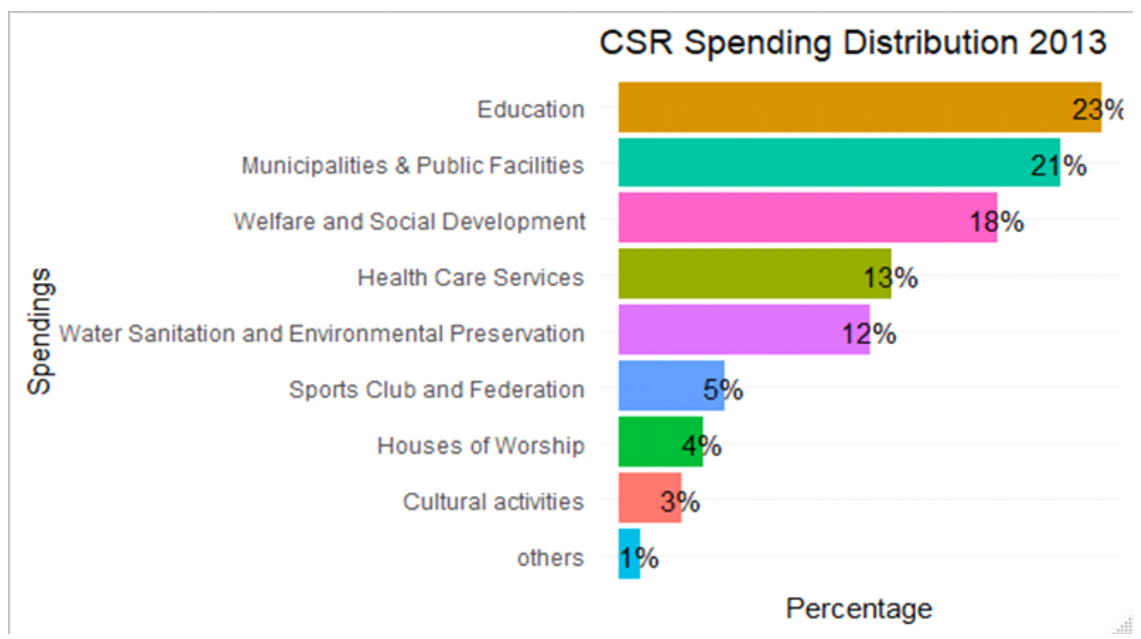

Figure 3: CSR Spending in 2013

Source: Worldfolio (2015). ${ }^{61}$

In tandem with the company's commitment to sustainable operations, it actively strives to reduce the effect of production activities on the

60 Khaled Al Tarawneh, "A Comprehensive Outlook of Mining Industry in Jordan, Opportunities and Threats" (2016) 06 Open Journal of Geology 1137 < http:// www.scirp.org/journal/doi.aspx?DOI=10.4236/ojg.2016.69084>.

61 Worldfolio (n 59). 
environment. Thus, it applies state-of-the-art technologies at its new plant as well as strict policies at all sites to minimize waste products, limit carbon and potash emissions and streamline water and energy consumption. Arab Potash Company further dedicates a portion of its CSR budget to finance both water and environmental projects. For instance, in 2013 alone, the company offered over 1.2 million JOD to provide support to the energy, water, marine, as well as recycling initiatives and societies. The company also performs several studies, including Initial Environment Evaluation (IEE) to measure the effect of potash production and its expansion on the environment. ${ }^{62}$ The items considered include higher emissions, number of trips to Aqaba, expansion of potash storage facilities as well as technical studies for determining the best ways of reducing stack emissions in order to conform to best global standards and practices. The environmental issues at the company's facilities and plants include dust emissions, trips, and waste water and oil.

\subsubsection{Dust Emissions}

Technical studies were carried out to understand this problem and reduce the number of emissions through the installation of a highly efficient baghouse filter system. ${ }^{63}$ This has been instrumental in minimizing emissions at the plants and the Aqaba facility. Three plants are already using this installed technology.

\subsubsection{Trips}

The company has undertaken various measures and continues instituting a plethora of mechanisms to minimize the number of trips that trucks made by increasing trailer or truck capacity and by substituting the carbon steel trailers. ${ }^{64}$ Additionally, new trailers will have a lower spillage on roads.

\subsubsection{Waste Water and Oil}

Lagoons for wastewater effluents have been constructed to address environmental needs. The company also reuses the treated effluent emanating from the town for irrigation. Also, it opened a new collection

62 Tarawneh (n 60).

63 Worldfolio (n 59).

64 ibid. 
and separation station for managing oil. ${ }^{65}$ Also for its future projects, the company has installed two ambient air monitoring stations for measuring airborne particles that emerge from its plants. From this case study, it is obvious that whereas the company may be contributing to some levels of pollution, it is critically contributing to economic growth, and socio-environmental development. ${ }^{66}$ Thus, it can be used as an example for other companies that are yet to embrace sustainability in their operations in the MENA region.

\section{ADVANCING THE SUSTAINABILITY DIMENSIONS OF MENA EXTRACTIVE INDUSTRIES: SOLUTIONS AND RECOMMENDATIONS}

The literature review and case studies discussed (Ma'aden Company, Kettara Mine, and Arab Potash Company) all show that the extractive industry can play a pivotal role in the attainment of the SDGs. Whereas these companies have historically contributed to socio-economic development in the past, their contribution to environmental and political stability remains low. There are several ways in which the extractive industry can contribute to the attainment of the SDGs. It already contributes to the resources required for internal consumption, taxation, products, and royalties destined for global trade. In the MENA region, petroleum and minerals could supply sectors that contribute to climate change mitigation technologies and the production of electronic and electrical equipment. Thus, there is a need for more improvements in national legislations and environmental governance pertaining to environmental monitoring within developing states. Since the SDGs focus on bringing about more comprehensive societal achievements, mining and petroleum corporations should think about how to increase their operations' scope to optimize their efforts geared towards sustainable development. While prioritizing activities within the MENA region, companies need to focus on three major development areas: enhancement of physical infrastructure, such as communications, water supply, and electricity, development of climate change resilience, and renewable energy, as well as education and health advances that include maternal medical care. Along with these solutions to the problems afflicting the extractive industry in the MENA region, the following recommendations

65 ibid.

66 ibid. 
will help the MENA countries to implement actions, policies, and activities that would help the attainment of the SDGs.

\subsection{Poverty Alleviation}

To contribute to maximally poverty alleviation, the extractive industry should make wage structures competitive in line with industry best practices and standards, including paying accurate royalties and taxes. It also ought to promote inclusive employment, develop effective procurement strategies, develop early warning systems, and plan for early livelihood restoration and resettlement. ${ }^{67}$ Companies in the extractive industries should also carry out due diligence, sustainable community development through corporate social responsibility programmes, and support livelihoods through non-mining strategies. In other words, poverty alleviation can be promoted by employment and better economic growth in the MENA region.

\subsection{Clean Water and Sanitation}

The respective governments have a major role to play in the provision of improved sanitation and clean water. This can be achieved through the establishment of policies aimed at environmental stewardship that should be prioritized by petroleum and mining sectors to ensure that minimal harm is done to water and people's health. This can be achieved by ensuring that water is available and sustainably managed. ${ }^{68}$ Water and sanitation principles need to be applied in the core business operations. Towards this end, there is a need for countries in the MENA region to encourage companies to recycle and conserve clean water through recycling, reducing, and reusing. Water quality should be monitored through participatory monitoring processes as a way of addressing risks and improving transparency. Also, these industries should embrace approaches to water quality and access, which consider community and stakeholders' need to make sure that the available water resources are

67 Jonathan Gamu, Philippe Le Billon and Samuel Spiegel, "Extractive Industries and Poverty: A Review of Recent Findings and Linkage Mechanisms" (2015), 2. The Extractive Industries and Society $162<$ https://linkinghub.elsevier.com/ retrieve/pii/S2214790X14000860>

68 Kai Lei, Huiyun Pan and Chunye Lin, "A Landscape Approach towards Ecological Restoration and Sustainable Development of Mining Areas" (2016) 90 Ecological Engineering $320<$ https://linkinghub.elsevier.com/retrieve/pii/ S0925857416300805>. 
not over-strained or contaminated. More importantly, companies in the extractive industry should extract responsibly, generate fewer wastes, utilize safer processes, and apply new sustainable technologies.

\subsection{Economic Growth and Decent Work}

Mining and petroleum companies in the MENA region should strive to stimulate economic growth through supplier development and local procurement strategies. They also ought to establish not only inclusive recruitment but also training and education to give equal access to different groups. Collaboration and leveraging on good relationships created are also crucial for building a sector-wide approach to issues. The industry should promote the wellbeing of the people and local communities by reducing emissions and improving environmental stewardship. ${ }^{69}$ They can also establish small businesses and business incubators to promote innovation and technological advancement that can lead to safer environments and economic growth.

\subsection{Political Stability and Robust Institutions}

The extractive industry should strive to reduce company-community conflicts to enhance peaceful and inclusive societies for sustainability. Human Rights Impact Assessments should be implemented along with other due diligence processes. Also, companies should take part in conflictfree mineral certification schemes and provide support for the implementation of relevant regulations. ${ }^{70}$ They should also take part in multi-stakeholder initiatives, uphold transparency, and adhere to the rule of law. Mineral and petroleum resources should not be used as a tool for gaining material resources to wage insurgencies but as a resource for empowering the people and building cohesive societies.

\subsection{Good Health and Wellbeing}

The extractive industry should strive to improve occupational health and safety. Companies should ensure that workers work in safe conditions. The integration of community health into the safety and

69 Mohamed Abdouli and Sami Hammami, "Investigating the Causality Links between Environmental Quality, Foreign Direct Investment and Economic Growth in MENA Countries" [2017] International Business Review.

70 Lanouar Charfeddine and Zouhair Mrabet, "The Impact of Economic Development and Social-Political Factors on Ecological Footprint: A Panel Data Analysis for 15 MENA Countries". 
health management systems should also be prioritized by implementing community health impact assessments. There is a need also to understand the scope of potential risks and emissions to people and water from the extractive industry and thus embrace responsible management plans and measures. ${ }^{71}$ Partnerships with governments, communities, and other stakeholders could also be critical for improving access to health services and responding to epidemics.

\subsection{Quality Education}

Mineral and petroleum extraction could also support quality education through the establishment of vocational, educational, and technical training programmes for the mining workforce. This can be achieved by companies collaborating to make sure that the national curriculum provides for the technical training needed in the extractive industry. ${ }^{72}$ Furthermore, these firms can invest in teacher training colleges and schools and also collaborate with the government and communities to enhance the availability and quality of educational opportunities. Specific care would be needed wherever skilled workers are not available within the local community.

\subsection{Affordable and Clean Energy}

The extractive industry is an inherently energy-intensive industry. The industry can enhance energy sustainability by hastening the application of energy efficiency measures as well as the adoption of renewable energy into mine power supplies. Moreover, it can partner with other organizations to promote the adoption of renewable energy. ${ }^{73}$ Whereas energy efficiency is not a crucial focus, mining could also leverage its demand for energy to extend power to areas with insufficient supply through partnerships that allow shared utilization of energy infrastructure. However, many of the companies remain reluctant to enter into renewable

71 Raimund Bleischwitz and others, "Resource Nexus Perspectives towards the United Nations Sustainable Development Goals" (2018) 1 Nature Sustainability 737 < http://www.nature.com/articles/s41893-018-0173-2>.

72 Philippe Le Billon and Elizabeth Good, "Responding to the Commodity Bust: Downturns, Policies and Poverty in Extractive Sector Dependent Countries" (2016) 3 The Extractive Industries and Society $204<$ https://linkinghub. elsevier.com/retrieve/pii/S2214790X15300137>.

73 Francesco Fuso Nerini and others, "Mapping Synergies and Trade-Offs between Energy and the Sustainable Development Goals" (2018) 3 Nature Energy 10 <http://www.nature.com/articles/s41560-017-0036-5>. 
energy industries because they believe it is not as lucrative as the nonrenewable energy industry. The historical failure of international oil and gas companies (BP, Exxon) demonstrates that these companies perceived wind and solar energies, along with electric vehicles, to be a direct threat to their business.

\section{CONCLUSION}

The shift towards sustainable development implies that all sectors, irrespective of their nature, have to play a crucial role in this challenging journey. The extractive sector plays a pivotal role in the economic development of many regions, but this has been mixed in the case of the MENA region. The region has vast mineral and oil resources but experiences widespread social unrest and political instability. Also, the unsustainable production methods in use make mining unsustainable in the region. Thus, only a few companies are trying to implement proactive measures for addressing sustainability challenges. This article has established that the extractive industry makes little contribution to political stability, economic growth, and socio-environmental development of the region despite the enormous capacity and potential of the industry. The three case studies provide insight that mining and petroleum companies should not be left behind in the quest for sustainability in the region. Addressing the challenges facing the region is only one part of the issue, but more needs to be done. More importantly, this article has shown that the industry can enhance the attainment of all the SDGs because of its economic power and the advantage of being an early industry in the region. As such, stakeholders should embrace and develop better mechanisms for ensuring that the MENA region embarks on a path of sustainability in their extractive industries. This would be critical for reversing the poor influence of the industry on sustainable development. This article has argued that the SDGs and Agenda 2030 pose a challenge to the extractive industry in the MENA region to go beyond their core business activities' scope to make a lasting impact on the poor communities in their countries. It implies that the existing stakeholder engagement strategies should increasingly focus on human development like the elimination of hunger and poverty. Innovative arrangements and cross-sector collaboration should be sought to attain the much-needed societal impact. The challenge ahead for the extractive industry in the MENA region, therefore, is embracing the SDGs and demonstrating leadership as well as a commitment to poverty reduction, health improvement, and peace. 